\title{
A postura inconstitucional do setor de comunicação brasileiro: 0 caso Empresa Brasil de Comunicação (EBC)
}

\author{
Marília Gabriela Silva Rêgo ${ }^{1}$ \\ Acsa Roberta Macena da Silva²
}

\begin{abstract}
Resumo
O presente artigo discute sobre as práticas inconstitucionais no sistema de comunicação brasileiro que dificultam a democratização da mídia. O trabalho aborda de maneira mais específica as investidas contra o setor público de comunicação, com ênfase na Empresa Brasil de Comunicação (EBC) que teve seu conselho curador destituído no governo Temer (2016-2018) e que, no primeiro semestre de 2019, na gestão Bolsonaro (PSL), vivenciou a fusão da TV Brasil (emissora pública) com a TV NBR (estatal). A investigação aponta que este último acontecimento contraria o princípio da complementariedade entre os sistemas privado, público e estatal previsto no Artigo 223 da Constituição Federal de 1988.
\end{abstract}

\section{Palavras-chave:}

Inconstitucionalidade. Complementaridade dos Sistemas. EBC

\begin{abstract}
This article discusses the unconstitutional practices in the Brazilian communication system that hinder the democratization of the media. The paper addresses in a more specific way the actions against the public communications sector, with emphasis on the Brazilian Communications Company (EBC), which had its trustee council removed from the Temer government (2016-2018) and which, in the first half of 2019, in the Bolsonaro (PSL) management, experienced the merger of TV Brasil (public broadcaster) with TV NBR (state). The investigation indicates that this last event contradicts the principle of complementarity between the private, public and state systems provided for in Article 223 of the Federal Constitution of 1988.
\end{abstract}

Keywords:

Unconstitutionality. Complementarity of the Systems. EBC

\footnotetext{
${ }^{1}$ Doutoranda e Mestre pelo Programa de Pós-Graduação em Comunicação da Universidade Federal de Pernambuco (PPGCOM/UFPE). marilia_gabriela00@ hotmail.com

${ }^{2}$ Mestranda pelo Programa de Pós-Graduação em Comunicação da Universidade Federal de Pernambuco (PPGCOM/UFPE). acsa.macena7@gmail.com
} 


\section{VOZES $_{\text {\&IÁLORO }}^{\mid}$}

Itajaí, v. 18, n. 01, jan/jun 2019

\section{Introdução}

O sistema de comunicação brasileiro é altamente concentrado nas mãos de grupos familiares, políticos e religiosos. O que vivenciamos é uma verdadeira oligopolização midiática que se expande através da Propriedade Cruzada (LIMA, 2011), isto é, um mesmo grupo controla diferentes veículos entre rádios, tvs, jornais e portais. Essa manobra de controle é comum no Brasil, onde os meios de comunicação de massa nasceram sob o modelo comercial norte-americano (JAMBEIRO, 2001).

Apesar disso, ensaia-se na Constituição Federal de 1988 a proibição aos oligopólios midiáticos (Art. 220, $\$ 5^{\circ}$ ), além da preferência de programações nos meios de comunicação com finalidade educativas, artísticas, culturais e informativas (Art. 221). Embora tenhamos o Capítulo $\mathrm{V}$ específico para a demanda sobre Comunicação e pluralidade de informação, não houve a regulamentação deste campo que é de fundamental importância para a condição da liberdade e da igualdade que definem a sociedade democrática (CHAUÍ, 2012).

Em tentativas de pluralizar esse setor, foi criada a Empresa Brasil de Comunicação (EBC), em 2007, como expressão de um sistema público de comunicação necessário. O artigo 223 da Constituição afirma que o serviço de radiodifusão precisa observar a existência dos sistemas comercial, público e estatal de forma complementar. Esse avanço, no entanto, encontrou fortes resistências de setores econômicos e políticos do país (LIMA, 2011), antes mesmo da aprovação da Medida Provisória № 398/2017 que no dia 7 de abril de 2008 se tornou a Lei № 11.652/2008 de criação da EBC.

Com o atraso de 60 anos em relação à mídia comercial, ainda são diversos os impasses para seu fortalecimento enquanto empresa pública de comunicação, tais como a independência de interesses do mercado econômico e, sobretudo, do Estado. Dessa forma, a tendência dos governos de impor controle sobre o oferecimento desse serviço (UNESCO, 2006) tem se apresentado como uma realidade no cenário do Brasil.

Nos últimos três anos, uma série de medidas têm sido capazes de suscitar o debate sobre o enfraquecimento do sistema público de comunicação do país. Entre elas está a publicação da Medida Provisória n⿳ำ 744/2016, em setembro de 2016, que resultou na destituição do Conselho Curador da EBC, órgão de representatividade da sociedade civil dentro da empresa; e a demissão do seu diretor-presidente, que pode ser nomeado e demitido a qualquer momento pelo Chefe do Executivo. Já em abril de 2019 foi autorizada pela Portaria № 219 a unificação da TV NBR (estatal) com a TV Brasil (pública), que cumpriam finalidades totalmente distintas.

Diante desses acontecimentos, o trabalho discute as práticas inconstitucionais no setor de comunicação do Brasil que dificultam a experiência de uma mídia democrática. O foco se dá ao sistema público de comunicação, com ênfase na EBC e no fato mais 


\section{VOZES $_{\text {\&DÁLORO }}^{\mid}$}

Itajaí, v. 18, n. 01, jan/jun 2019

recente, acontecido em 9 de abril de 2019, da fusão da TV NBR com a TV Brasil. A pesquisa parte da compreensão de que o oferecimento do serviço público de comunicação é capaz de ampliar a oferta de conteúdos e garantir a existência de uma mídia igualitária.

Metodologicamente, o trabalho perpassa a revisão bibliográfica (GIL, 2008) para nortear o estudo sobre o sistema público de comunicação. $\mathrm{O}$ artigo foi conduzido como estudo de caso da EBC, pois está relacionado a um período de profundas mudanças advindas dos governos Temer (PMDB) e Bolsonaro (PSL). Além disso, outra técnica foi a análise de documentos que, de acordo com Gil (2008, p. 45), “(...) vale-se de materiais que não recebem ainda um tratamento analítico, ou que ainda podem ser reelaborados de acordo com os objetos da pesquisa”. Assim, foram analisados os seguintes documentos: a) Medida Provisória: $n^{\circ}$ 744/2016 do ex-presidente Michel Temer; b) Portaria n²16; c) Capítulo V da Constituição Federal de 1988; d) Lei nº 11.652 (7 de abril de 2008), que criou a EBC e d) Plano de Governo de Lula, Dilma, Temer e Bolsonaro.

\section{Entre a concentração midiática brasileira e o que diz a Constituição de 1988}

A história da radiodifusão do país é marcada essencialmente pela propriedade privada. Desde o século passado, ainda em 1924, os Diários Associados de Assis Chateaubriand se constituíram como o maior conglomerado de mídia (LIMA, 2006). Somente perdeu a primeira posição para as Organizações Globo, de Roberto Marinho, fundada posteriormente, em 1965, e que é atualmente a maior rede de empresas de comunicação do país. Para se ter uma ideia, ainda no período da Ditadura Militar do Brasil (1964-1985), concessões públicas de rádio e televisão foram dadas paras as emissoras que ainda hoje são líderes no mercado.

Assim, o Brasil ocupa a $11^{\text {a }}$ posição (a última) dentre os países investigados pela Pesquisa de Monitoramento da Propriedade da Mídia no quesito "diversidade de mídia"3 e não há uma legislação no país que impeça um mesmo grupo controlar outros meios de comunicação. $\mathrm{O}$ capítulo $\mathrm{V}$ da Constituição é o menos regulamentado, ou seja, é o que recebeu menos legislação infraconstitucional para tirar do papel e gerar princípios a serem implementados, de modo que a nossa estrutura midiática permanece majoritariamente nas mãos dos mesmos grupos e que cada vez se mostram mais consolidados.

A legislação da comunicação brasileira compreende basicamente os veículos de radiodifusão (rádios e tvs) e telecomunicações (telefonia, internet). Para veículos impresso, sites e portais da internet não há qualquer restrição de controle, nem necessidade de

\footnotetext{
${ }^{3}$ Os dados são da Pesquisa de Monitoramento da Propriedade da Mídia, promovida pela Organização Repórteres sem Fronteiras (Alemanha) e executada no Brasil em parceria com o coletivo Intervozes.
} 


\section{VOZES $_{\text {\&DÁLORO }}^{\mid}$}

Itajaí, v. 18, n. 01, jan/jun 2019

obtenção de uma outorga ou licença. No caso da mídia impressa, a única legislação sobre o tema, a Lei de Imprensa, foi anulada pelo Supremo Tribunal Federal em 2009, mas mesmo esta não trazia exigências claras no tocante a concentração (INTERVOZES, 2017).

Essa concentração da mídia ainda revela que $80 \%$ dos grupos de controle estão nas regiões sul e sudeste do Brasil. Para alcançar outras regiões, a estratégia é criar afiliadas. Assim, olhando para as emissoras de TV no seu cenário atual, enxergamos uma liderança de grupos familiares, políticos e religiosos. Nesta ordem de liderança de audiência está a Globo com 36,9\% (família Marinho); seguida pelo SBT com 14,9\% (Família Abravanel); a Record, com 14,7\%, do Bispo Edir Macedo, líder da Igreja Universal Reino de Deus (IURD), igreja que também está à frente do Partido Republicano Brasileiro (PRB); Bandeirantes (Família Saad) com 4,1\%; e RedeTV, com 1,2\% (Grupo Amilcare Dallevo / Marcelo de Carvalho).

A Constituição Federal de 1988 também próibe que políticos estejam ligados a empresas de mídia. Porém, um estudo mais recente realizado em 2018 pelo coletivo Intervozes investigou candidatos à eleição para os cargos de deputado federal e estadual, senador e governador e revelou que pelo menos 34 dos elegíveis são donos de emissoras de rádio e TV, a maior parte com carreira política consolidada e tentando reeleição (16 deles). É o que Venício Lima (2011) chama de “coronelismo eletrônico”. Os próprios parlamentares, que não deveriam ser concessionários e nem estarem envolvidos nos processos de renovação de suas emissoras no congresso, influenciam diretamente e votam a favor de si mesmos.

\section{Serviço público de comunicação: cidadãos $X$ consumidores}

Diante de um território midiático acompanhado de fenômenos que inviabilizam a construção de uma mídia plural e igualitária, se faz necessário refletir sobre a importância do sistema público de comunicação. Considerado como um pilar central para as sociedades democráticas, o serviço é entendido, inclusive pela Organização das Nações Unidas para a Educação, a Ciência e a Cultura, como urgente "para salvaguardar la integridad y los intereses de los "ciudadanos" (UNESCO, p. 27, 2006).

Como resposta à necessidade de um sistema público no Brasil, o artigo 223 da Constituição Federal abriu espaço para muitas interpretações e disputas. O texto atribui a responsabilidade ao Poder Executivo de “outorgar e renovar concessão, permissão e autorização para o serviço de radiodifusão sonora e de sons e imagens, observando o princípio da complementaridade dos sistemas privado, público e estatal” (BRASIL, 1988).

Para Venício Lima (2011), o objetivo do constituinte era corrigir o inquestionável desequilíbrio histórico existente entre esses sistemas, com a hegemonia do sistema privado. Dessa forma, se faz necessária a discussão sobre como a existência dos três sistemas deve 


\section{VOZES $_{\text {\&IÁLORO }}^{\mid}$}

Itajaí, v. 18, n. 01, jan/jun 2019

ser complementar e quais são suas diferenciações. Se trata de uma tentativa de delimitar possíveis fronteiras tanto relacionadas ao financiamento e a gestão, como também quanto ao conteúdo que deve ser oferecido pelo sistema público.

Em 2009 foi realizada a primeira Conferência Nacional de Comunicação (Confecom) em Brasília. O evento abriu uma ampla discussão a respeito das políticas para comunicação e regulação dos meios. No geral foram aprovadas cerca de 600 propostas, sendo apenas sete do Grupo Temático que trouxe a discussão sobre sistemas público, privado e estatal; tributação; financiamento e competição. Porém, as proposições ainda permanecem no papel, a exemplo da proposta de fortalecimento dos "meios de comunicação não comerciais, por meio da revisão da legislação vigente - no que se refere a fontes de financiamento e pilares da programação - e das exigências relativas às outorgas” (CONFECOM, 2010, p.199).

Ainda na $1^{\text {a }}$ Confecom, a diferenciação sobre o sistema público, privado, e estatal do país, respectivamente, foi melhor definida pela sociedade por meio da PL 361, aprovada no Grupo Temático que tratava sobre o marco legal e regulatório da comunicação. O documento expressa a necessidade de regulamentar o Artigo 223 da Constituição, definindo que

O primeiro [público] deve ser entendido como aquele integrado por organizações de caráter público geridas de maneira participativa a partir da possibilidade de acesso universal do/a cidadão/s a suas estruturas dirigentes e submetido a controle social. O segundo [privado] deve abranger todos os meios de entidades privadas em que a natureza institucional e o formato de gestão sejam restritos, sejam estas entidades de finalidade comercial ou não comercial. O terceiro [estatal] deve compreender todos os serviços e meios controlados por instituições públicas vinculadas aos poderes do Estado nas três esferas da Federação (CONFECOM, 2010, p. 201).

Há quase uma década após a primeira e única conferência feita, o desafio continua. Há uma preocupação em garantir a diversidade dos diferentes segmentos da sociedade (gênero, classe, étnica-racial), que se apresenta sem representatividade nos conteúdos veiculados pelos grandes meios privados. Assim, a universalidade, a diversidade, a independência e a diferenciação (UNESCO, 2006, tradução nossa), que são as principais funções que devem estar presentes no oferecimento do serviço, se tornam inviáveis.

A universalidade se trata do alcance a todos os cidadãos, sem diferenciá-los quanto ao seu nível social. Já a diversidade reflete na variedade de oferta de conteúdos para o público que possui diferentes expectativas. A independência, por sua vez, implica na expressão de ideias, críticas, informação e opiniões de maneira livre de interesses comerciais ou governamentais. A diferenciação está voltada à qualidade e características na programação que devem ir além do que é comumente oferecido pela mídia comercial. 


\section{VOZES $_{\text {\&DÁLORO }}^{\mid}$}

Itajaí, v. 18, n. 01, jan/jun 2019

Vale ressaltar que a independência é um elemento crucial para efetivação do serviço público. Isso porque emissoras submissas aos interesses do mercado ou dos governos não ofertam "à sociedade as alternativas culturais que estão vocacionadas a oferecer: programações com um olhar crítico distanciado do poder e do próprio mercado” (BUCCI; CHIARETTI; FIORINI, 2012, p. 13).

Apesar do sistema comercial ter maior alcance no território brasileiro, seu interesse voltado essencialmente ao lucro deixa de atender aos anseios de uma população que carece de mecanismos para o exercício da cidadania. Como considera Denis McQuail (2003, p.144), a base comercial "desloca a responsabilidade das normas, ética, valores, etc., para a sociedade". Bucci, Chiaretti e Fiorini (2012, p. 15) também pontuam que "no campo estético, o alvo da radiodifusão pública deve ser o de desconstruir a aura da mercadoria”, pois a informação pública não pode ser tratada como negócio econômico.

\section{A linha tênue entre o sistema público e o estatal: a questão do interesse público}

O serviço oferecido pelo sistema estatal ou governamental é comumente confundido com o público. Apesar de também precisar possuir conteúdo que preze pelo interesse público, a principal função do estatal deve ser a abordagem das informações relevantes acerca das atividades do governo. Elas não podem ser utilizadas como instrumento de propaganda governista, mas sua pauta deve ser orientada por "princípios constitucionais da moralidade, da legalidade e da impessoalidade” (BUCCI, p. 76, 2015).

Nessa perspectiva, Jorge Duarte (2007, p.3) defende que o campo da comunicação pública é capaz de incluir "tudo que diga respeito ao aparato estatal, às ações governamentais, partidos políticos, terceiro setor e, em certas circunstâncias, às ações privadas”. Assim, quando compreendemos a comunicação governamental ou estatal também como pública, é necessário ressaltar que "trata-se de uma forma legítima de um governo prestar contas e levar ao conhecimento da opinião pública os projetos, ações, atividades e políticas que realiza e que são de interesse público” (BRANDÃO, 2006, p.3).

Eugênio Bucci (2015, p.75) ainda acredita que o sistema estatal deve ser definido "pelo que são capazes de perguntar ao poder, não pelo que respondem em nome do poder”. Ele ressalta que em muitos países europeus, a presença de forças comerciais e governamentais não foram permitidas pela sociedade que queria superar os traumas dos regimes totalitários após a Segunda Guerra Mundial.

No Brasil, o desentendimento sobre a diferenciação e a necessidade da existência do sistema privado, público e estatal tem gerado uma série de ações que vão de encontro com as características de cada um desses serviços. Logo, as condições para efetivação do oferecimento do serviço público de comunicação no país ainda se apresenta tardio. A 


\section{VOZES $_{\text {\&DÁLORO }}^{\mid}$}

Itajaí, v. 18, n. 01, jan/jun 2019

participação de organizações da sociedade civil na construção de um debate de promoção do setor ainda não se mostraram capazes de exercer influência significativa. Na verdade, conforme abordaremos adiante, não têm peso na correlação de forças que define as políticas públicas do setor (LIMA, 2011).

\section{Um olhar sobre as políticas públicas de comunicação para a Empresa Brasil de Comunicação (EBC)}

Durante a década de 1990, com a política neoliberal iniciada em Collor e concretizada em Fernando Henrique Cardoso (PSDB), houve bastante incentivo para a privatização de alguns setores (rodovias federais, bancos, empresas de energia). Na contramão estiveram os investimentos para as emissoras de TVs públicas mantidas pelo Estado que, por falta de capital, foram sucateadas ao ponto de, se não levadas à extinção, o seu enfraquecimento. No governo de Luiz Inácio Lula da Silva (PT) vemos um início de preocupação com este setor passando a ser mais efetivamente debatido com a sociedade civil.

Na reeleição em 2007, seu plano de governo discutia a "democratização dos meios de comunicação, permitindo a todos o mais amplo acesso à informação" (PLANO DE GOVERNO LULA, 2007, p.13). Porém, até hoje o debate existe sem a efetiva medida para alcançar uma comunicação descentralizada. Ainda em abril de 2019, na primeira entrevista concedida pelo ex-presidente após sua prisão ${ }^{4}$, Lula reconheceu ter errado em não regulamentar os meios de comunicação.

Sua sucessora, Dilma Rousseff, também não conseguiu propor um debate eficaz sobre o assunto. No plano de governo da ex-presidente, o planejamento estava voltado no interesse de "construir igualmente mecanismos que protejam todas as formas de comunicação - a internet, em particular - assegurando a privacidade da cidadania, das empresas e dos Governos" (PLANO DE GOVERNO DILMA, 2014, p. 26). Assim, em seu governo, o momento mais expressivo dentro do campo da Comunicação foi o Marco Civil da Internet (Lei № 12.968/2014), responsável por regular o uso da internet no país.

Apesar desses fatos, um ano depois do segundo mandato do governo Lula, através da aprovação da Lei 11.652/2008, foi criada a Empresa Brasil de Comunicação. A EBC surgiu a partir das estruturas da antiga Radiobrás e das TVEs do Rio de Janeiro e Maranhão ${ }^{5}$

\footnotetext{
${ }^{4}$ O ex-presidente responde a processo na Operação Lava Jato, sendo acusado de ter recebido um apartamento tríplex na praia do Guarujá, em São Paulo, como propina da construtora OAS. Isso em troca de benefícios em contratos na Petrobras durante o governo do PT.

${ }^{5}$ Em maio de 2019, a produção da TV Educativa do Maranhão foi encerrada pela direção da EBC. Nesse ano, a emissora completaria 50 anos de história, sendo a primeira do país a transmitir aulas por meio do tele-ensino, além de ter se tornado referência para outras tevês educativas.
} 


\section{VOZES $_{\text {\&IÁLORO }}^{\mid}$}

Itajaí, v. 18, n. 01, jan/jun 2019

e foi criada para regulamentar a radiodifusão pública brasileira. A empresa reúne veículos de radiodifusão públicos, sendo o principal deles a TV Brasil.

Ainda quando criada, foi estabelecido na lei da EBC que seu compromisso deveria estar voltado ao desenvolvimento da "consciência crítica do cidadão, mediante programação educativa, artística, cultural, informativa, científica e promotora de cidadania” (Lei № 11.652). Além disso, outro objetivo traçado foi o desenvolvimento da "construção da cidadania, a consolidação da democracia e a participação da sociedade, garantindo direito à informação, à livre informação do pensamento, à criação e à comunicação" (Ibdem).

Entre seus órgãos de gestão, a lei previa a existência de um Conselho Curador, que contava com 22 membros, entre os quais 15 representantes da sociedade civil, 4 do Governo Federal, 2 do Congresso Nacional (Câmara e Senado) e um dos funcionários da EBC. O conselho era responsável por acompanhar a linha editorial da empresa, que passou a ser constantemente denunciada pelos funcionários logo após a sua destituição pela Medida Provisória no 744/2016, do ex-presidente Michel Temer ${ }^{6}$ (PMDB).

Com a Medida Provisória, Temer autoriza o Poder Executivo a interferir na EBC e determina que ela seja administrada por um Conselho de Administração e por uma Diretoria Executiva (Art.12), além da ordenação de que a escolha do diretor-presidente é de responsabilidade do Ministro de Estado Chefe da Casa Civil da Presidência da República.

Com essa decisão, a qualquer momento o diretor-presidente da empresa pode ser demitido, ação que vai de encontro com o mandato fixo que visava assegurar a independência da EBC perante o governo. Desde 2016, após à publicação da MP e exoneração do jornalista Ricardo Melo, já passaram pela empresa quatro diretorespresidente em menos de três anos. Em fevereiro de 2019, Luiz Antonio Ferreira, que havia sido nomeado ainda na gestão Temer, foi demitido por não concordar com o plano de reestruturação na empresa estudado pelo governo Bolsonaro.

Apesar de considerar as medidas do governo Temer como uma tragédia sobre a EBC, Eugênio Bucci, ex-presidente da estatal Radiobrás, pontua que a empresa nunca se colocou como uma verdadeira empresa pública de comunicação. Bucci (2016) considera que a sua inicial vinculação à Secretaria de Comunicação Social da Presidência da República já determinava que haveria interferência do Planalto em seu conteúdo.

Em contrapartida, ele defende que a empresa deveria ter sido ligada ao Ministério da Cultura, como ocorre nas principais democracias que possuem organismo de comunicação pública. No entendimento de Bucci (2016, p. 42), “os governos Dilma e Lula

\footnotetext{
${ }^{6}$ É relevante perceber que, não por acaso, uma das ações iniciais do governo Temer foi a de modificar o Ministério das Comunicações, de foco exclusivo da área comunicacional e unificá-lo na pasta do Ministério da Ciência e Tecnologia, tornando-se o Ministério da Ciência, Tecnologia, Inovações e Comunicações (MCTIC).
} 


\title{
VOZES $_{\text {\&DÁLORO }}^{\mid}$
}

Itajaí, v. 18, n. 01, jan/jun 2019

diziam que não, mas gostavam de ter ao alcance da mão o controle político da empresa, para qualquer eventualidade”.

\section{Políticas para a comunicação pública na gestão Bolsonaro: 0 caso TV Brasil}

Com a eleição presidencial de 2018, o atual Presidente da República Jair Bolsonaro, ainda em seu Plano de Governo lançado durante a candidatura, demonstrou pouca atenção ao setor de comunicação. Não há qualquer menção ao sistema público de comunicação. Inclusive, no item "Imprensa Independente", espaço dedicado às propostas para a comunicação, há uma forte oposição à regulação da mídia, como vemos no trecho:

\begin{abstract}
Somos defensores da Liberdade de opinião, informação, imprensa, internet, política e religiosa!; Liberdade das pessoas e de suas famílias em poder escolher os rumos da vida na contínua busca da felicidade! ; Somos contra qualquer regulação ou controle social da mídia; A Liberdade é o caminho da prosperidade; Não permitiremos que o Brasil prossiga no caminho da servidão; Nosso povo deve ser livre para pensar, se informar, opinar, escrever e escolher seu futuro (PLANO DE GOVERNO BOLSONARO, 2018, p.18, grifo nosso).
\end{abstract}

Existe uma nítida confusão no entendimento dos termos "regulação" e "controle social da mídia”, associados neste trecho à censura. Regular a mídia não é censurá-la. Pelo contrário, significa determinar regras para o funcionamento da comunicação que é um serviço público e assim romper com a hegemonia privada, democratizando o setor. A Constituição pede que seja regulamentada, mas a ausência regulatória em mais de vinte cinco anos após sua promulgação demonstra a falta de compreensão e interesse político e econômico em realizá-la. Sobre essa incompreensão, Ivan Moraes Filho (2016) já alertava:

\footnotetext{
"Regulação é censura”, ouve-se sempre quando alguém ousa questionar as normas que regem a comunicação no Brasil. "Para quê gastar dinheiro público em emissoras que não dão audiência:", dizem outros para se opor a eventuais investimentos por parte do Estado em veículos de mídia pública. Muito do que se discute (e do que se omite) sobre políticas de comunicação no Brasil é recheado de preconceitos, fruto provável da falta de compreensão sobre esse direito e de informação sobre a importância de se poder debater (e receber informações diversas) livremente no espaço público (MORAES FILHO, 2016, p. 49)
}

Ainda nos 100 primeiros dias do governo Bolsonaro, aconteceu um episódio de investida à Constituição no que se refere à Comunicação. Em 9 de abril de 2019, a TV NBR, emissora estatal, foi incorporada à TV Brasil, emissora pública, através da Portaria- 


\section{VOZES $_{\text {\&IÁLORO }}^{\mid}$}

Itajaí, v. 18, n. 01, jan/jun 2019

Presidente $\mathrm{n}^{\circ}$ 216, assinada pelo atual diretor-presidente da EBC, Alexandre Henrique Graziani Jr.

Controversamente, a decisão diz preservar o princípio da complementaridade dos sistemas público, privado e estatal (Art. 223 da Constituição) sem prejuízo (Art. $2^{\text {o }}$ da Portaria). Há, aparentemente, mais uma confusão na interpretação, desta vez sobre o termo "complementaridade". A ideia de sistemas complementares sugere a coexistência individual dos sistemas privado, público e estatal, como já discutimos mais acima, visando garantir o direito de produção e veiculação de conteúdo pelos três sistemas, além de permitir a existência de um ambiente plural no qual diferentes veículos, vozes e representações estejam presentes (MORAES FILHO, 2016). Assim, complementaridade não significa fundir uma TV em outra.

A finalidade das duas emissoras é totalmente distinta. A TV NBR, inaugurada em 13 de junho de 1998, no governo de Fernando Henrique Cardoso, é vinculada à Secretaria Especial de Comunicação Social da Presidência da República e foi pensada para tornar visíveis as ações do executivo, assim como fazem outras Tvs estatais como a TV Câmara, a TV Justiça e a TV Senado. Antes de ser fundida, a emissora era responsável pela cobertura dos eventos do Poder Executivo Federal. Em 2007, com a Criação da EBC, a NBR passou a ser de responsabilidade da empresa para cumprir o princípio da transparência do poder público, expresso no artigo 37 da Constituição Federal.

Já a TV Brasil, por sua vez, é uma emissora pública nacional. A programação da emissora possui conteúdo infantil, jornalístico e de entretenimento, além de produções direcionadas a pessoas com deficiência, à exemplo do Programa Especial, que conta com a primeira repórter com Síndrome de Down na equipe. Nos últimos dois anos, a audiência da TV cresceu 64\%, segundo o Painel Nacional de Televisão, se tornando em janeiro de 2019 a sétima emissora mais assistida. Somente no primeiro semestre de 2018, a sua programação gerou "mais de 4.200 matérias, notas e citações em jornais, revistas, blogs e sites especializados" (PASSOS et. al., 2018).

Portanto, a junção dos dois sistemas distintos nos permite observar a incompreensão sobre a importância de cada um, assim como a tentativa de marcha-à-ré no que propõe a própria constituição. Argumentamos que o processo de unificação entre as referidas TVs consiste em uma tentativa de extinguir o projeto de TV pública uma vez que pretende descaracterizá-la. Em nota publicada sobre os impactos da portaria para o sistema público de comunicação, o Conselho Curador cassado demonstrou preocupação com a unificação e considerou que "cada uma tem a sua função específica, ambas essenciais para o exercício pleno da democracia em um país que garanta as liberdades constitucionais" (MEMÓRIA CONSELHO CURADOR, 2019). 


\section{VOZES $_{\text {\&DÁLORO }}^{\mid}$}

Itajaí, v. 18, n. 01, jan/jun 2019

\section{O que mudou na Tv Brasil?}

No dia 10 de abril de 2019, foi ao ar a nova TV Brasil, após a fusão com a TV NBR. Com a integração, houve mudança da logomarca da emissora que antes era totalmente azul e passou ser verde e amarelo, concretizando simbolicamente o projeto de ligação com o governo através das cores da bandeira. No site da empresa foram descritas as permanências e alterações da grade de programação, a exemplo da inserção de flashes ao vivo da Presidência da República e dos ministérios ao longo da programação, sob a justificativa de que esses conteúdos do governo são de interesse público.

De acordo com a publicação, programas consagrados estão mantidos como o "Repórter Visual" (programa jornalístico com recursos de acessibilidade), "Sem Censura" (programa de entrevistas) e "TV Brasil Animada" (animações infantis). As mudanças começam a se inserir progressivamente com programas que demonstram os interesses do executivo. Aos domingos (6h) passa a ser exibido um programa sobre o agronegócio nacional, já confirmado pelo site da TV Brasil.

Também existem programas ainda em fase de preparação a serem implantados. Segundo matéria publicada pelo Brasil de Fato, ainda no mesmo mês de inauguração da nova grade, os novos programas a serem veiculados apresentam conteúdo relacionado à valorização das Forças Armadas, sendo "dois para a Marinha do Brasil, um para o Exército e outro sobre a Missão Antártica”, que também envolve a participação da Força Aérea Brasileira (FAB) (BRASIL DE FATO, 2019).

Ainda sobre essas mudanças na programação, o Conselho Curador, que antes de ser destituído tinha a responsabilidade de observar a linha editorial adotada pela empresa, acredita que essas modificações estão relacionadas com a "intenção de usar o prestígio alcançado pela TV Brasil, ao se manter este ano como a sétima emissora mais assistida do país, inclusive entre as TVs pagas, para fazer propaganda governamental” (MEMÓRIA CONSELHO CURADOR, 2019).

Essa intenção de legitimar os atos oficiais do governo através da TV Brasil é reforçada por Vancarlos Alves, seu gerente executivo. Ele pontua que "a junção das duas TVs em uma grade, agregará valores e servirá de fonte com credibilidade para os atos do governo" (TV BRASIL, 2019). No entanto, apesar do conteúdo relacionado aos atos do governo se constituir como pauta para o interesse público, cada sistema possui seu papel. A cobertura em destaque de atividades governamentais cabe a uma emissora estatal; à pública, cabe a veiculação de temas advindos da demanda da sociedade civil.

Reforçando esta ideia de separação entre a TV estatal e a TV pública, Bucci alerta sobre esta última ter uma gestão de caráter independente, distanciando-se de uma ligação com o Governo, entendendo que a "independência em relação ao poder (governamental ou econômico) é pré-requisito para a interdependência da emissora pública em suas 


\section{VOZES $_{\text {\&IÁLORO }}^{\mid}$}

Itajaí, v. 18, n. 01, jan/jun 2019

relações com a sociedade" (BUCCI, 2010, p. 7 apud JAMBEIRO, FERREIRA e MORAIS, 2016, p.183).

\section{Considerações finais}

Diante do histórico de poucas políticas públicas para o fortalecimento do campo da comunicação pública e das recentes investidas contra a EBC e TV Brasil, o artigo reacendeu o debate da necessidade de uma regulação do setor de comunicação brasileira. O alerta sobre os conglomerados de mídia tem sido feito há algum tempo através de estudos como os de Eula Cabral (2015) e Venício Lima (2015) demonstrando a necessidade de olharmos para o que constituímos como comunicação no país. Sem a implementação e debate de políticas públicas para o setor, dificilmente teremos uma mídia democrática.

A necessidade da regulamentação de leis, a partir das demandas do Capítulo V da Constituição Federal, deve ser o ponto de partida para evitar a concentração. Segundo Lima (2016), uma vez implementada a legislação - e reforçamos ainda a necessidade de uma fiscalização rigorosa - teríamos a diminuição de oligopólios, a promoção da cultura nacional e regional nas programações, o incentivo a produções independentes e a observância da complementaridade dos sistemas privado, público e estatal (LIMA, 2016).

Este último tema, inclusive, se estabeleceu como um ponto de destaque desenvolvido no trabalho, tendo em vista os acontecimentos mais recentes na TV Brasil encarados como mais uma tentativa de sufocar a comunicação pública do país. Inserir uma TV de cunho estatal em uma pública é, além de inconstitucional, o resultado do desinteresse em manter canais públicos que historicamente lutam pela pluralidade de discursos que levem em conta a diversidade de gênero, raça e etnia dos cidadãos.

A partir desse "gancho" da diversidade é que também entendemos como elemento fundamental na efetivação de um projeto de comunicação pública a ativa participação da sociedade civil na gestão, produção e conteúdo veiculado pela empresa. Assim, a existência de um conselho curador é um elemento crucial para a observância da qualidade do conteúdo produzido pela emissora.

Temos presenciado inúmeras tentativas de desestabilizar a Comunicação Pública em nosso país. Porém, ao mesmo tempo que há a desestabilização da consolidação desse espaço, reforça-se o empenho em pesquisas e debates sobre esse tema tão importante para a vivência democrática, partindo do princípio que fazer comunicação plural e de qualidade é um ato de resistência. 


\section{VOZES $_{\text {\&IÁLORO }}^{\mid}$}

Itajaí, v. 18, n. 01, jan/jun 2019

\section{Referências}

CONFECOM, Conferência Nacional de Comunicação. Caderno da $\mathbf{1}^{\underline{a}}$ Conferência Nacional de Comunicação. 2010. Disponível em: $<$ http://pfdc.pgr.mpf.mp.br/atuacao-econteudos-deapoio/publicacoes/comunicacao/caderno-propostas-1a-confecom>. Acesso em 04 de maio de 2019.

BRASIL. Lei Federal no 11.652. Sete de abril de 2008. Disponível em: <http://www.planalto.gov.br/ccivil_03/_ato2007-2010/2008/lei/111652.htm>. Acesso em: 10 de março de 2019.

Constituição Federal de 1988. Disponível em: < http://www.planalto.gov.br/ccivil_03/constituicao/constituicao.htm >. Acesso em: 10 de março de 2019.

BRASIL DE FATO. Novo plano de Bolsonaro estreia esta semana: uma TV estatal verde-oliva. Disponível em: < https://www.brasildefato.com.br/2019/04/08/novoplano-de-bolsonaro-estreia-esta-semana-uma-tv-estatal-verde-oliva/ >. Acessado em 04 de maio de 2019.

BUCCI, Eugênio. O estado de Narciso: a comunicação pública a serviço da vaidade particular. São Paulo: Companhia das Letras, 2015.

; CHIARETTI, Marco; FIORINI, Ana Maria. Indicadores de qualidade nas

televisões públicas - uma avaliação contemporânea. Representação no Brasil da UNESCO, Série Debates CI, No10: Janeiro de 2012, 35 p. Disponível em: <http://unesdoc.unesco.org/images/0021/002166/216616por.pdf>. Acesso em 30 de mar. de 2019.

CONGRESSO NACIONAL. Medida Provisória nº 744, de 2016. Disponível em: https://www.congressonacional.leg.br/materias/medidas-provisorias/-/mpv/126826> Acesso em 06 de maio de 2018.

DUARTE, Jorge. Comunicação Pública. 2007. Disponível em: < http://jforni.jor.br/forni/files/ComP\%C3\%BAblicaJDuartevf.pdf>. Acesso em: 20 de abr. de 2019.

FUNDAÇÃO PERSEU ÁBRAMO. Marilena Chauí fala sobre o poder da mídia. Disponível em: < https:/fpabramo.org.br/2012/09/03/marilena-chaui-fala-sobre-o-poderda-midia/>. Acessado em 13 de setembro de 2018.

INTERVOZES. Marco Regulatório do Sistema de Mídia Brasileiro.2017. Disponível em: < http://brazil.mom-rsf.org/br/ > . Acessado em 09 de maio de 2018.

JAMBEIRO, Othon. A TV no Brasil no século XX. Salvador: EDUFBA, 2001.

LIMA, Venício. Regulação das Comunicações: História, poder e direitos. São Paulo: Paulus, 2011. - (Coleção comunicação). 


\section{VOZES $_{\text {\&DÁLORO }}^{\mid}$}

Itajaí, v. 18, n. 01, jan/jun 2019

MEMORIA CONSELHO CURADOR. Nota do Conselho - Sob gestão do governo, portaria da EBC tenta acabar com projeto de TV Pública. Disponível em: <http://conselhocurador.ciranda.net/blog/nota-do-conselho-governo-publica-portariainconstitucional-para-tentar-acabar-projeto-de-tv-publica>. Último acesso em: 15 de mai. de 2019.

MORAES FILHO, Ivan. Sobre a mídia que queremos: comunicação pública, direitos humanos \& democracia. Olinda: Centro de Cultura Luiz Freire, 2016.

PASSOS, Gésio (et. al). EBC: em defesa da comunicação pública. Disponível em $\langle$ https://emdefesadaebc.files.wordpress.com/2018/11/resumodossie2cor.pdf $>$. Acesso em: 02 de abril de 2019.

PLANO DE GOVERNO JAIR BOLSONARO. Disponível em: <http://divulgacandcontas.tse.jus.br/candidaturas/oficial/2018/BR/BR/2022802018/28000 0614517/proposta_1534284632231.pdf >. Acesso em 05 de maio de 2019.

PLANO DE GOVERNO LULA. Disponível em: $\langle\underline{\text { http://csbh.fpabramo.org.br/uploads/Programa_de_governo_2007-2010.pdf } 〉 . ~ A c e s s o ~}$ em 05 de maio de 2019.

PLANO DE GOVERNO DILMA ROUSSEFF. Disponível em: $<$ https://www.pt.org.br/wp-content/uploads/2014/07/Prog-de-Governo-Dilma-2014INTERNET1.pdf $>$. Acesso em 05 de maio de 2019. 